\title{
Paying kidney donors: time to follow Iran?
}

\author{
Rupert WL Major*
}

Since the first kidney transplant was performed over fifty years ago, it has offered the chance of life and the freedom from dialysis for thousands of people. However, demand for organs has always exceeded supply. The gap between the two is widening due to increased prevalence of diseases common to a 'western' lifestyle such as diabetes and hypertension, leading to more chronic kidney disease and renal failure.

Renal transplants differ from most other transplants because living people are able to donate without significant adverse effects on their own health. Donated kidneys, therefore, have a potential to become a commercial asset. They can be harvested from cadavers or from living human donors. Living Related Donation (LRD) has become the organ source of choice and most common method. Supply, however, is still greatly inferior to demand: the United States Department of Health and Human Services 2006 Annual Report recorded over 82,000 patients on the waiting list for a kidney, up nearly $7 \%$ from the previous year (1).

In order to resolve the shortage of donors, some have advocated financial payments being made to donors. Despite being illegal in most countries, the trade appears to be booming in nations such as Turkey, Russia, and South Africa (2). Just as waiting lists and costs motivate some people to travel outside of their country of residence for procedures such as hip replacements and cosmetic surgery - a phenomenon called 'health tourism', a similar phenomenon appears to be occurring on a smaller scale for organ transplants (3). The dilemma physicians and health officials are faced with is whether to close their eyes to this trade, disregarding ethical implications and the adverse effects of surgeries done on the black market, or to legalize it and try to establish boundaries to protect organ donors that receive compensation.

Currently, the World Health Organisation estimates that of the 660,000 people in the world who require any form of transplant, $10 \%$ receive one each year (4). Of these, $10 \%$ receive their transplant through commercial

*To whom correspondence should be addressed: Rupert Major

26 Burns Street, Leicester, Leicestershire, UK, LE2 6DB Email: Rm157@le.ac.uk 'transplant tourism' (4). The lack of donors and the rise of 'transplant tourism' have recently forced regulatory organisms throughout the world to act. The European Union tried to boost organ donations by suggesting a Europe-wide donor card, and has formed a regulatory body to standardize quality and safety within transplantation in an effort to reduce commercial transplants. The People's Republic of China, which performs more transplants per year than any other country except the USA (5), has recently introduced tougher restrictions and penalties for commercial transplantation (5).

One of the few countries that has legalised the sale of organs is Iran (6). The first kidney transplant in Iran took place forty years ago. However, in the following twenty years only one hundred were performed overall within Iran. This was mainly due to the lack of infrastructure available to develop and maintain a kidney transplant network within the country. In the early 1980's, the Iranian government recognized the increasing strain on dialysis resources as the end stage renal failure population grew in Iran. The government began to pay for its citizens to have living related transplants abroad, the majority in the UK. Four hundred such transplants were funded in a five year period (5). As these costs started to spiral, a small network of renal transplantations teams was set up within Iran and just under one hundred transplants were carried out per year from 1985 to 1987 (6). The development of an Iranian renal transplant network of this size was a drop in the ocean compared to over 25,000 people living with end-stage renal disease in Iran, many of which live in rural areas and do not readily have access to medical care (6).

In 1988, Iran legalized living non-related donation (LNRD) of kidneys and established an associated transplantation system. This government-organized system regulated and funded the transplantation process and compensated the donors for their organ. A thirdparty independent association was set up to arrange contact between donors and recipients. This agency, the Dialysis and Transplant Patients Association (DTPA), still carries out this function to this day and is staffed on a voluntary basis by end-stage renal failure patients. An 
important problem with this system is that human leucocyte antigen (HLA) matching of tissues, necessary to improve the chance of graft survival and prevent host rejection, is not routinely performed. .

Within the first year of the establishment of this system, the number of transplants had almost doubled; nearly four fifths were from living unrelated sources (6). In addition to payment from the government, donors also receive free health insurance and often payment from the recipient or a charity. The receiver of the 'new' kidney is provided with highly subsidized immunosuppression and charitable organizations allow those unable to pay for the transplant themselves to receive a new organ. Importantly, it is illegal for the medical and surgical teams involved or any 'middleman' to receive payment (6). A potential donor is also not allowed to contact anyone on the waiting list. Despite, this, anecdotal stories of young men touting their 'spare' kidney in dialysis clinics are common (7).

There is no nationwide transplant registry in Iran so the outcomes of renal transplantation, regardless of source, are difficult to assess. However, the Hashemi Nejad Hospital (HNH) in Tehran, one of the leading hospitals in Iran, does provide detailed analysis of its data. In the twenty years up to the beginning of 2006, just under two thousand transplants in $\mathrm{HNH}$ were performed, three quarters of which were LNRD (4). Despite no HLA matching, results are similar in terms of both graft and patient survival between LNRD and LRD in both Iran and other countries $(6,7)$. The extrapolation of these results to other, smaller centers in Iran is however limited.

Whilst still illegal in 'Western' nations, could the 'Iranian model' of payment for LNRD be used in North America or Europe to solve the problems of kidney donor shortages? A hotly disputed topic is whether the Iranian system has actually cleared the waiting list for transplants and whether LNRD is the true answer to the problem (7). Advocates of the Iranian model insist that where there was once a significant waiting time in excess of the length in 'Western' nations, there is now no waiting time. Further, there are "no significant differences" in groups of donors and recipients when compared in terms of socioeconomic background (wealth and education level). Thus significant social exploitation is not occurring (7). It should be noted, however, that investment in cadaveric donation programs has allowed them to increase significantly, and they now accounts for more than $10 \%$ of transplants (6) (however, this is compared with almost $60 \%$ in the US (8)). The Iranian system is known to have ethical and legal loopholes which have been exposed and exploited. One of the earliest problems involved patients from abroad travelling to Iran to receive a kidney donation from an Iranian. This practice was outlawed to prevent the development of true 'transplantation tourism' and international exploitation of Iranian donors. In addition, refugee groups (such as those from Afghanistan) are offered transplants but are not allowed to donate to people outside of their ethnic groups, further decreasing potential exploitation of vulnerable groups (6).

Opponents of the Iranian system insist that the system is not as perfect as it seems. There is evidence to suggest Iran's system has not cleared its waiting list and that trading between socioeconomic classes is a substantial problem (7). Critics of the Iran model would argue that even this well developed system has major flaws and that a ban on payment to LNRD should be maintained in other parts of the world.

Outside of Iran, the issue continues to be highly contentious. The end-stage renal failure population continues to increase in most countries, putting an increasingly heavy load on medical infrastructure. Compensation for living non-related donors, once a taboo subject, has now begun to be discussed openly in transplantation meetings and the medical literature (9, $10,11)$. The advocates for legalization argue that each of us has autonomy over our own body in every aspect of our health and that from this stems the right to donate a kidney to a related or non-related patient. Payment for sperm and eggs is legal in many countries, even though they arguably have greater long-term implications due to the potential to create a whole new individual. Similarly to compensation received for participation in some clinical trials, the individual also gains no immediate benefit from putting themselves at risk. However, opponents argue that the donation of a kidney is permanent, which sets it apart from the examples given above. LNRD supporters argue that after the initial peri-operative risk, the donor has no long term increased risk of mortality (12). Furthermore, the risk surrounding the surgical procedures is low in most centers, with a $0.02 \%$ risk of death during surgery and its immediate complications and less than a $1 \%$ risk of other morbidities (12). Most importantly, in the longer term, a recent meta-analysis has shown that there is no significant acceleration in decrease in glomerular filtration rate (beyond that expected due to aging) in kidney donors fifteen years after transplantation (13).

It could be argued that if the medical profession truly believes in full patient autonomy, care requested with informed consent by a patient should be allowed provided a fair, regulated system is in place. As with recreational drug use, it is a question society faces in many areas: is the harm of the activity in question reduced and better controlled in a regulated market? As ESRF continues to grow in prevalence, the problem of 
unregulated organ markets and brokers is likely to become more severe. It is argued that the setting up of regulated markets would 'cut out the middleman' and reduce the exploitation of individuals and developing nations. In situations where there are no regulations, the donors are maximally exploited and are often left with no supportive care once donation has taken place (3). In addition, inferior surgical and medical practice, common on the black market, leave both the donor and recipient at greater risk whilst the broker pockets a large cut of the proceeds.

A possible compromise is a non-monetary reward system. For instance, patients who have previously agreed to be on the transplant list could receive priority health care. It has also been suggested that governments should control the monetary aspects of the transactions rather than payment passing directly from individual to individual. The donor would effectively sell their organ to the state which would then allocate it on the basis of clinical need. By making the process more medically transparent, it may placate to some degree those who accuse pro-monetary transplantation advocates of disregarding the exploitation of the poor by the rich. It is also likely that a 'fair' standard price could be set to prevent those in desperate financial need from being even further exploited. Using economic cost-effectiveness analyses, a figure of approximately $\$ 90,000$ US ( $£ 45,000$ or 67,000 Euros) has been proposed (14), much less than the estimated cost of dialysis of up to \$70,000US per annum per patient (15). Government intervention would also guarantee adequate post-operative care and follow-up for the donor, something which is currently limited.

Finally, the medical profession's view on the ethics of commercial transplantation must be considered. The consensus within the transplantation community is largely against LNRD legalization but increasingly, voices are calling for its allowance. The World Health Organization is strongly opposed to payment for any form of organ (17). This has been partly shown in primary care physicians with $90 \%$ and $20 \%$ in favour of related and non-related kidney transplants respectively (although there was no mention of commercial payment in the non-related cases) (16). In addition, the overall view appears to be negative towards those who would be actually carrying out the transplantation. The role of commercial transplantation surgeons has cheekily been described in an article in the British Medical Journal as "Rotten Jobs" that consist of "harm[ing] a poor person and sav[ing] a rich one" (18).
As the pressure of demand for organs continues to increase rapidly, the idea of financial compensation for LNRD of kidneys will continue to be with us. Until an alternative to human donors can be found, either artificial or xenotransplantation (animal) based, then this ethical issue will continue to be discussed and considered within transplantation and wider medical communities. Whether talk will ever be turned to action in favour of monetary payments to donors remains to be seen. The medical profession may not agree with payments on an ethical level but the increasing problems caused by prohibition of LNRD and the prolific black market of transplants are starting to be considered as good reasons for legalization and tight regulation.

\section{REFERENCES}

1. http://www.ustransplant.gov, US Department of Health and Human Services, 2006 OPTN/SRTR Annual Report

2. Finkel M. This little kidney went to market. New York Times Magazine. 27 May 2001:28

3. Scheper-Hughes N. Keeping an eye on the global traffic in human organs, The Lancet 2003, 361:1645-1648

4. Legal and illegal organ donation, The Lancet, 369:1901

5. Watts J. China introduces new rules to deter human organ trade, The Lancet, 369:1917-1918

6. Ghods AJ and Savaj S. Iranian Model of Paid and Regulated Living-Unrelated Kidney Donation. Clin J Am Soc Nephrol 2006; 1:1136-1145

7. Griffin A. Kidneys on Demand. BMJ 2007; 334:502-505

8. United States Renal Data System. Annual Report 2006. http://www.usrds.org/

9. Friedman EA and Friedman AL. Payment for donor kidneys: Pros and cons. Kidney International 2006; 69:960-962

10. Friedman AL. Payment for living organ donation should be legalised. BMJ 2006;333:746-8

11. Harris $\mathrm{J}$ and Erin C. An ethically defensible market in organs. BMJ 2002;325:114-115

12. Matas AJ et al. Morbidity and mortality after living kidney donation, 1999-2001: survey of United States transplant centres. American Journal of Transplantation 2003;3:830-4

13. Garg et al. Proteinuria and reduced kidney function in living kidney donors: A systematic review, meta-analysis, and metaregression. Kidney International 2006;70:1801-1810

14. Matas AJ and Schnitzler M. Payment for living donor (vendor) kidneys: a cost-effectiveness analysis. American Journal of Transplantation 2003;4:216-221

15. The Cost Effectiveness of Kidney Transplantation. UK Transplant. Updated January 2007. (www.uktransplant.org.uk/ukt/newsroom/fact_sheets/cost_effec tiveness_of_transplantation_2007-01.doc)

16. Conesa $\mathrm{C}$ et al. Primary Care Doctors Faced With Living Organ Donation. Transplantation Proceedings. 2006:38(3);863-5

17. Guiding principles on human organ transplantation. World Health Organisation. http://www.who.int/ethics/topics/ transplantation_guiding principles/en/index1.html

18. Black M. Rotten jobs. BMJ 2007;334:750

Rupert Major is an undergraduate fourth year medical student at the University of Leicester. Although currently undecided on a potential career path after graduation, he is interested in internal medicine, particularly nephrology and cardiology. 